\title{
THE EFFECT OF SILANE COUPLING AGENT ON IRON SAND FOR USE IN MAGNETORHEOLOGICAL ELASTOMERS \\ PART 1: SURFACE CHEMICAL MODIFICATION AND CHARACTERIZATION \\ K. L. Pickering ${ }^{1 *}$, S. Raa Khimi ${ }^{1}$ and S. Ilanko ${ }^{1}$ \\ ${ }^{1}$ School of Engineering, The University of Waikato, Hamilton, 3216, New Zealand \\ *Corresponding author: Tel: +64 078384672; email address: klp@waikato.ac.nz
}

\begin{abstract}
Bis-(3-triethoxysilylpropyl) tetrasulphane (TESPT) was employed for surface modification of iron sand for use in magnetorheological elastomers (MREs). The amount of TESPT was varied at five levels (2,4,6,8 and 10wt\%) relative to iron sand content to assess the optimum amount of coupling agent for interfacial bonding and damping performance. Evidence that coupling had occurred between iron sand and TESPT was identified by Raman Spectroscopy and the grafting percentage was determined by thermogravimetric analysis. Subsequently, isotropic MREs containing unmodified and modified iron sand particles and natural rubber were prepared. Crosslink density assessment by swelling testing provided evidence that the tetrasulphane group of TESPT formed crosslinks with the rubber chains. The results exhibited the advantages of TESPT as a coupling agent between iron sand particles and rubber and also revealed that 6\% TESPT content produced the highest crosslink density. The effects of the amount of TESPT on dynamic mechanical properties the morphological characteristics of the MREs were also investigated.
\end{abstract}

Keywords: A. Particle-reinforcement; B. Interface/interphase; D. Surface analysis; E. Surface treatments

\section{INTRODUCTION}


Magnetorheological elastomers (MREs) are a new group of damping materials which consist of a non-magnetic matrix (normally an elastomer) containing a suspension of magnetically permeable particles. The most commonly used magnetic particles for MREs are carbonyl iron particles and suitable matrix materials include natural rubber, silicone rubber, polybutadiene, polyisobutylene, polyisoprene, and polyurethene rubber [1-7]. The main advantage of MREs is that the damping and stiffness can be varied by application of an applied magnetic field during fabrication or in service. Damping occurs by the viscous flow of the rubber matrix and inclusion of magnetic particles in rubber enables additional damping through magnetic particle interaction and interfacial damping. MREs can be classified into two kinds: isotropic MREs and anisotropic MREs. Isotropic MREs can be characterized by having a uniform magnetic particle distribution in the matrix. Anisotropic MREs have a special chain-like structure of magnetic particles in a matrix resulting from curing the matrix under an applied magnetic field. Over the past few years, MREs have attracted increasing attention and have been considered for applications such as adaptive tuned vibration absorbers [8], automotive engine mounts [4] and semi active seismic dampers [9].

New Zealand iron sand possesses physical and magnetic properties that make it suitable for use in MREs. Compared to commonly use magnetic particles, such as pure iron and carbonyl iron, iron sand has a number of advantages, including high permeability and saturation magnetisation, low cost and it is readily available in New Zealand. It is derived from erosion of andesitic and rhyolitic volcanic rocks which are the main types of iron ore deposits in New Zealand. Iron sand is a dark, high-density sand that occurs along the west coast of the North Island from Wanganui to Kaipara Harbour near Auckland, over a distance of $480 \mathrm{~km}$. It contains titanomagnetite, a mineral containing iron and titanium, which is highly magnetic [19, 20]. 
Similarly for all MREs, the damping of MREs depends not only on the types of rubber matrix and magnetic particles, but also on the level of adhesion between the particles and the rubber matrix such that the strength of interaction between the particles and matrix has to be sufficiently strong to obtain efficient interfacial damping. For MREs this sets a challenge. Here, as for other MRE components, the incompatibility of the inorganic magnetic fillers and the matrix can actually lead to poor wettability and adhesion between the filler and matrix as well as nonuniformity of filler dispersion leading to low energy absorption [10-12]. Therefore, it is sensible to modify the surface of the iron sand in order to improve ease of adhesion with and dispersion within the rubber matrix in order to realise the full potential of MREs.

Surface modification of inorganic particles can be achieved using a number of approaches [13]; most commonly, the filler surface is chemically modified to become more compatible with the matrix using methods such as polymer coating [14], surfactant absorption [15] and bifunctional coupling agent treatments $[16,17]$. Among various modification approaches, the bifunctional coupling agent treatment using silane based coupling agents is the most successful and cost effective treatment for improving the adhesion between inorganic particle and rubber matrix. These chemicals are silicon-based chemicals that contain hydrolysable groups (such as methoxy, ethoxy or acetoxy) at one end that will interact with inorganic materials and organofunctional groups (such as amino, vinyl or sulphide) at the other end that can react with the rubber matrix. Therefore, inorganic and organic materials can be coupled together with the silane coupling agent acting as a bridge between them. Although this type of surface modification is well established for enabling different types of fillers such as silica [18, 19], aluminium powder [20], halloysite nanotubes [21], wood flour [22] and natural fibre [23, 24] to be used as reinforcement fillers in rubber compounds, its effect on inorganic magnetic particles for used in MREs has not been 
extensively studied. Some research has been reported on modification of carbonyl iron particles using silane coupling agents used as a filler in silicon rubber $[25,26]$ and polyurathene rubber [16] based MREs; the results showed that the mechanical and damping performance of MREs increased due to increased dispersion and interaction between particles and the matrix. Although it is accepted that the effectiveness of silane to interact with the substrate is dependent on a number of factors including hydrolysis time, presence of solvent, temperature and $\mathrm{pH}$ [27], none have assessed the optimum silane content coupled to the particles to allow for improved subsequent bonding. Furthermore, as far as the authors are aware, there is no work carried out on surface modification of inorganic magnetic particles for use in natural rubber based MREs.

In this study, isotropic MREs based on iron sand and natural rubber were prepared. Bis-(3triethoxysilylpropyl) tetrasulphane (known as TESPT or Si 69) which is the most popular and effective silane coupling agent for hydrocarbon rubber (see Figure 1) was used for surface modification of iron sand particles [13]. TESPT contains ethoxy hydrolysable groups at both ends that enable the silicon groups to bond with iron sand particles and the tetrasulphane group of its centre which is capable of bonding with the rubber matrix. Iron sand contains stable oxides that potentially have reactive sites including $\mathrm{Fe}-\mathrm{O}$ bonds and $\mathrm{OH}$ groups on their surface $[28,29]$. Therefore, there is potential for improvement of iron sand and natural rubber interaction by using TESPT as a coupling agent. The effects of TESPT content on dynamic mechanical properties were investigated using two methods. The loss tangent, commonly called tan $\delta$, is considered as the fundamental parameter to assess damping. Tan $\delta$ gives a comparison of the energy lost to that stored; it is obtained by dividing the loss modulus $\left(\mathrm{G}^{\prime \prime}\right.$ or $\left.\mathrm{E}^{\prime \prime}\right)$ by the storage modulus ( $\mathrm{G}^{\prime}$ or $\left.\mathrm{E}^{\prime}\right)$ [30]. The other estimate of damping used was the amount of energy dissipated during cyclic deformation, which can be calculated from the area of the hysteresis loop (hysteresis loss). 


\section{EXPERIMENTAL}

\section{Materials}

Natural rubber (SMR L grade) and other chemicals including zinc oxide, stearic acid, ncyclohexyl-2-benzothiazole sulfenamide (CBS), tetramethylthiuram disulphide (TMTD), paraffin oil, and naphthenic oil were all purchased from Field Rubber Limited, Auckland. Bis-(3triethoxysilylpropyl) tetrasulphane (TESPT) was purchased from Leap LabChem Co. Limited, China. Iron sand was collected from Ngarunui Beach, Raglan. The iron sand was milled using a planetary mono mill (Pulverisette 6) produced by Fristech $\mathrm{GmbH}$ and subsequently sieved to obtain a 45-56 $\mu \mathrm{m}$ particle size.

\section{Surface Modification of Iron Sand Particles}

The surface modification of iron sand particles was carried out by an aqueous alcohol solution method. The particles were subjected to surface treatment with TESPT at 2, 4, 6, 8, 10\% by weight (wt\%) of the particles. An aqueous alcohol solution of $95 \%$ ethanol was used and the $\mathrm{pH}$ of the solution was adjusted with acetic acid to $4.0-4.5$. The TESPT of predetermined quantity was dispersed in the ethanol solution at a ratio of 1:100 and the mixed solution was stirred for 5 minutes to assure the hydrolization of the silane coupling agent. The iron sand particles were then added and stirred for an additional 30 minutes at room temperature to ensure a uniform distribution of the coupling agent on the surface of iron sand particles. The mixture was filtered and washed three times with ethanol to remove unreacted coupling agent. The treated iron sand particles were then dried at $80^{\circ} \mathrm{C}$ in an oven until a constant weight was achieved.

Preparation of iron sand-natural rubber isotropic MREs 
The compound formulation used in this study is given in Table 1. Formulations were compounded using a conventional laboratory two roll mill (model XK150) according to ASTM designation D3184-80. The front roller speed was $23.86 \mathrm{rpm}$ and the rear roller speed was $32.81 \mathrm{rpm}$, diameter of rolls was $150 \mathrm{~mm}$, friction ratio of two rolls was 1:1.4 and the roller temperature was set at $80^{\circ} \mathrm{C}$. The nip gap (distance between front and back roller) was maintained at $2 \mathrm{~mm}$ during compounding. The compounding began with softening the rubber on its own in the two roll mill (mastication). Mastication reduces the viscosity and increase the plasticity of natural rubber which is brought about by heat generated in two roll mill through conduction from the heated roller and shearing of rubber during milling. After mastication, during which the rubber had become invested on the hot roll (2-3 minutes), additives (other than accelerators and sulphur) were then added followed by iron sand; addition of accelerators and sulphur were delayed to the last part of the process to prevent premature vulcanization during compounding. The mixing time was approximately 40 minutes. The cure time at $150^{\circ} \mathrm{C}$ was then determined according to the procedure as described in reference [31] and the results are shown in Table 1. Compounded rubber samples weighing $13 \mathrm{~g}$ were placed in a mould $60 \times 50 \times 3 \mathrm{~mm}$ and were cured in a compression moulder at $150^{\circ} \mathrm{C}$ under a pressure of approximately $12 \mathrm{MPa}$

\section{Raman spectroscopy}

Raman spectra were acquired with a Ramanstation 400R (PerkinElmer) spectrometer equipped with an air cooled charged coupled device (CCD) detector and data points were recorded at 1 $\mathrm{cm}^{-1}$ intervals. The excitation source was a $785 \mathrm{~nm}$ near infrared laser focused on surface of samples with a spot approximately $200 \mu \mathrm{m}$ in diameter. Calibration was validated against a polystyrene standard disk (PerkinElmer) prior to measurement. Samples were analysed while placed on aluminium foil. The Raman instrument was visually focused onto the surface of each 
location to be analysed on the modified iron sand samples. Laser power was set to approximately $40 \mathrm{~mW}$ ( $40 \%$ of maximum, estimated to be $6 \times 105 \mathrm{~W} / \mathrm{m}^{2}$ on the $200 \mu \mathrm{m}$ diameter spot) to acquire spectra from all samples (after initial trials) for consistency across the range of materials analysed. Spectra were collected over the range $3200-200 \mathrm{~cm}^{-1}$ and each spectrum was acquired as the sum of five repeats of 60s exposures on the sample. Five separate spectra were acquired at different locations on each sample analysed.

\section{Thermogravimetric analysis}

The grafting percentage of silane coupling agent with iron sand particles was determined by thermogravimetric analysis (TGA) using an TA Instrument SDT 2910 thermal analyser operated in dynamic mode, heating from ambient temperature to $300^{\circ} \mathrm{C}$ at $5^{\circ} \mathrm{C} / \mathrm{min}$ in air purged at 150 $\mathrm{ml} / \mathrm{min}$ with an empty pan used as a reference. Thermal gravimetric curves were obtained. The grafting percentage was calculated as the fraction of the mass of grafted silane coupling agent divided by the mass of iron sand particles at $280^{\circ} \mathrm{C}[32,33]$ as follows:

$$
\text { Silane grafting }(\%)=\frac{\text { Grafted silane coupling agent } / g}{\text { iron sand particles } / g}
$$

The amount of grafted silane coupling agent was calculated from the weight loss of treated iron sand at $280^{\circ} \mathrm{C}$ minus weight loss of iron sand particles at $280^{\circ} \mathrm{C}$.

\section{Crosslink Density}

Determination of crosslink density in MREs was obtained using a swelling test. MREs samples with dimensions of $30 \mathrm{~mm} \times 5 \mathrm{~mm} \times 3 \mathrm{~mm}$ were weighed, and then immersed in toluene for 72 hours at room temperature in a dark environment. The toluene was replaced at 24 hours intervals over this time to minimise interference from toluene soluble fractions remaining in the samples. After 72 hours, samples were drained and dried and the swollen mass was recorded. Samples were then dried at $80^{\circ} \mathrm{C}$ in an oven until a constant weight was achieved. For each experimental point, 
3 samples were produced and the average values were calculated. The crosslink density was calculated by applying the Flory-Rehner equations as follows [34]

$$
\begin{gathered}
V_{r}=\frac{V_{p}}{V_{p}+V_{s}}=\frac{\frac{m_{d r y}}{\rho_{r}}}{\left(\frac{m_{d r y}}{\rho_{r}}+\frac{m_{w e t}-m_{d r y}}{\rho_{s}}\right)} \\
{[X]=\frac{-\left[\ln \left(1-V_{r}\right)+V_{r}+\chi V_{r}^{2}\right]}{V_{o}\left(V_{r}^{\frac{1}{3}}-\frac{V_{r}}{2}\right)}}
\end{gathered}
$$

where $V_{r}$ is the volume fraction of MREs, $m_{\text {wet }}$ is the swollen equilibrium mass, $m_{\text {dry }}$ is the dry MREs mass, $\rho_{\mathrm{r}}$ is the density of natural rubber $\left(910 \mathrm{~kg} / \mathrm{m}^{3}\right), \rho_{\mathrm{s}}$ is the density of toluene $\left(866 \mathrm{~kg} / \mathrm{m}^{3}\right)$, $[X]$ represents the crosslink concentration in $\mathrm{mol} / \mathrm{cm}^{3}, \chi$ is the interaction parameter between the rubber and toluene (0.393) and $\mathrm{V}_{\mathrm{o}}$ is the molar volume of toluene $\left(106.4 \mathrm{~cm}^{3} / \mathrm{mol}\right)$.

\section{Morphology}

The microstructures of isotropic MREs were observed using a Hitachi S-4700 scanning electron microscope (SEM). The samples were frozen and snapped into pieces to expose their interior and coated with a thin layer of platinum prior to observation at an accelerating voltage of $20 \mathrm{kV}$.

\section{Dynamic mechanical analysis}

Dynamic mechanical analysis was carried out using a Perkin Elmer dynamic mechanical analyser (DMA 8000). Tan $\delta$ was measured over a wide range of frequency, strain amplitude and temperature. The influence of frequency and strain amplitude on $\tan \delta$ was assessed using two circular disc specimens with a diameter of $10 \mathrm{~mm}$ and a thickness of $3 \mathrm{~mm}$ in shear mode at room temperature. Tan $\delta$ was measured over the frequency range of $0.01-130 \mathrm{~Hz}$ at a fixed strain amplitude of $0.5 \%$ and over a strain amplitude range of $0.1-4.5 \%$ at a fixed frequency of $100 \mathrm{~Hz}$. For the influence of temperature on $\tan \delta$, the samples were analysed in dual cantilever mode at a 
frequency of $1 \mathrm{~Hz}$, with a strain amplitude of $0.5 \%$ over a temperature range of $-100-50{ }^{\circ} \mathrm{C}$. The samples were rectangular with dimensions $30 \mathrm{~mm} \times 6 \mathrm{~mm} \times 3 \mathrm{~mm}$.

\section{Hysteresis}

Hysteresis loss is defined as the amount of energy dissipated during cyclic deformation when the samples are stretched and then allowed to retract at the same rate to the unstretched state. In this

study, the hysteresis loss was determined for tensile dumbbells using an Instron 4204 at a crosshead speed of 500mm/min according to ASTM D412-80. The stress-strain curve was recorded and hysteresis loss was calculated as

Hysteresis loss = Area under the loading curve - Area under the recovery curve

\section{RESULTS AND DISCUSSION}

\section{Characterization of surface modified iron sand particles}

Figure 2 shows a schematic of the potential reaction mechanisms of TESPT with iron sand particles. In the presence of water in an ethanol solution and under acid catalysed conditions the ethoxy reactive groups of the silane are hydrolysed thereby forming silanol groups

$(-\mathrm{Si}-$ $\mathrm{O}-\mathrm{OH})$ and liberating ethanol $[35,36]$. The silanol groups are highly reactive intermediates which are presumed responsible for bond formation with the iron sand. When iron sand was added into the solution, the hydroxyl groups on the surface of the iron sand is believed to react with the silanol groups and subsequent drying condenses silanol groups to form siloxane linkages. Evidence for this was provided by Raman Spectroscopy analysis of unmodified and modified iron sand particles as shown in Figure 3. For iron sand, a number of peaks can be seen including a broad peak between 1100 and $1900 \mathrm{~cm}^{-1}$, similar to observation elsewhere [37]. The growth of peaks at around $300 \mathrm{~cm}^{-}$ ${ }^{1}$ for all modified iron sand particles is indicative of the formation of Si-O-iron sand and/or Si-O- 
Si bonds that would occur during reaction of iron sand with TESPT, although, the latter could also occur due to polymerisation of TESPT to produce siloxane; however, production of siloxane would not be expected to improve interfacial bonding. The increased height of the peaks around 1400 $\mathrm{cm}^{-1}$ (representing $\mathrm{CH}_{2}$ bending in TESPT) from 0 to $6 \mathrm{wt} \%$ TESPT followed by no further increase from $6 \mathrm{wt} \%$ onwards suggests that coverage of iron sand particles by TESPT increases to $6 \mathrm{wt} \%$ when it reaches a saturation coverage [38].

Figure 4 shows TGA curves for unmodified and modified iron sand particles at different TESPT contents. All samples showed weight loss over the temperature range of $50^{\circ} \mathrm{C}$ to $280^{\circ} \mathrm{C}$ with weight increase above $280^{\circ} \mathrm{C}$ which is believed to have resulted from the oxidation of iron sand particles [39]. Similar trends have been observed in TGA curves for other magnetite particles [40]. As can also be seen, the unmodified iron sand particles were relatively stable in the air and only slightly weight loss between $100^{\circ} \mathrm{C}$ to $280^{\circ} \mathrm{C}$ which was probably due to vaporization of physically absorbed water at the surface of iron sand particles. The weight losses for modified particles increased with increasing TESPT content until 6\% and then reduced for $8 \%$ and $10 \%$ TESPT. The weight loss for modified particles could be attributed to the decomposition and evaporation of silane coupling agent on the surface of iron sand particles such that suggests the silane coupling agent is strongly bound to particle surfaces by what is expected to be covalent bonds [41]. The amount of TESPT attached to the surfaces of iron sand particles was quantitatively determined by TGA (taking the loss due to physically absorbed water into account) over the temperature range of $50^{\circ} \mathrm{C}$ to $280^{\circ} \mathrm{C}$ (each value representing an average from 3 samples) and is presented in Figure 5. It was not possible to conduct TGA analysis of TESPT on its own, however, a separate experiment was conducted where TESPT was heated at $280^{\circ} \mathrm{C}$ in a furnace for which a residual weight of only $0.6 \%$ was obtained. Thus, residual TESPT is not considered to have a 
significant effect on the obtained data. It can be seen that the percentage of grafted silane appears to increase with increasing TESPT content until it reached a maximum value at 6\% TESPT and thereafter decreased for higher TESPT contents (8\% and 10\%). At high TESPT content, the potential for hydrolysed TESPT to react with itself to produce polymeric siloxane increases as an alternative to reacting with iron sand. This polymeric siloxane could act as a barrier between TESPT and iron sand preventing reaction, particularly given that the siloxane polymer can react with multiple $\mathrm{OH}$ groups on the iron sand particles and screen other $\mathrm{OH}$ groups between those bonded with polymeric siloxane as described in the literature [42]. Polymeric siloxane that has not reacted with $\mathrm{OH}$ groups on iron sand would easily have been removed by washing the modified iron sand with ethanol and evaporation by drying during the preparation of the modified particles. This was checked by an extra wash with dichloromethane (DCM) following three times washing with ethanol for which the TGA weight loss and silane grafting percentage was found to be no significant different with those washed using just ethanol. Any remaining unreacted polymeric siloxane may also form e.g. oligomers by hydrogen bonding to the grafted TESPT such that may weaken the composites properties since the silane molecules may not link the filler to the matrix [42].

Figure 6 shows a schematic of possible reaction mechanisms for the tetrasulphane group of TESPT with natural rubber. The tetrasulphane group of the TESPT could have been first dissociated during the compounding process to produce sulfidic radicals that subsequently react either directly or through sulphur crosslinking agent $\left(\mathrm{S}_{\mathrm{x}}\right)$ with the rubber molecules in the presence of accelerators at elevated temperature during vulcanization to form crosslinks with the rubber molecules [43-45]. Evidence for this would be provided by crosslink density measurements of MREs filled with unmodified and modified iron sand particles at different TESPT contents as 
shown in Figure 7. It can be seen that the crosslink density gradually increased as the TESPT content increased from $2 \%$ to $6 \%$; this highlights the potential formation of new crosslinks in the rubber network due to interaction between tetrasulphane group of TESPT with the rubber molecules. In order to assess the time required for the tetrasulphane group of TESPT to react with rubber and form crosslinks, another compound was prepared, the same as that containing 6 wt\% silane coupling agent except that the sulphur crosslinking agent was excluded. It was found that the compound cured in 5.63 minutes which is not too different from time used here supporting substantial TESPT rubber crosslinking could have occurred. At higher TESPT contents (8\% and $10 \%)$ the crosslink density decreased which is not surprising given the evidence from TGA results that at such TESPT contents less silane is coupled to the iron sand, which would be expected to lead to less crosslinking between iron sand and rubber. The obtained results support the use of TESPT as a coupling agent for iron sand particles and natural rubber and also a content of $6 \%$ TESPT is more suitable than $8 \%$ and $10 \%$ TESPT.

\section{Morphology}

Figure 8 shows SEM images of fracture surface of isotropic MREs with unmodified and modified iron sand particles. It can be seen for unmodified particle MREs, the surface is smooth with less matrix tearing and uneven distribution of iron sand particles in the rubber matrix. Clearly, there are a lot of cavities remaining due to the particle pull out from the rubber matrix and obvious gaps between iron sand particle and rubber, suggesting weak interaction between iron sand and rubber (Figure 8 a). In Figure 8 b, the surface of isotropic MREs with modified iron sand particles is rougher due to matrix tearing than for MREs with unmodified particles. It is also evident that iron sand particles are more evenly dispersed in the rubber with much less aggregates in the matrix. 
Clearly, much less particle pullout can be seen supporting improved interfacial adhesion between iron sand and natural rubber suggesting stronger interaction between iron sand and rubber was obtained by using modified iron sand particles supporting Si-O-iron sand bonding.

\section{Dynamic Mechanical Properties}

The variation of $\tan \delta$ with frequency for MREs with different TESPT contents is shown in Figure 9a. Tan $\delta$ is the highest for the MREs with modified iron sand treated with 6\% TESPT and the increases in $\tan \delta$ compared to MREs with unmodified iron sand is on average $40 \%$ over the whole frequency range explored. G' and G” are also plotted in Figure 9 (b and c) to help highlight the mechanisms involved. G' and G”, similar to tan $\delta$ are frequency dependent. It can be seen that the increase of $\tan \delta$ as the frequency increased, is mainly due to increasing G” as opposed to changes in G'. The increased energy loss is assumed to be due to covalent bonding bringing about more intimate contact between the particles and rubber such that during deformation, increasing energy is expended overcoming friction, physical bonding as well as covalent bonding. At high TESPT content ( $8 \%$ and $10 \%)$, the lower $\tan \delta$ values could again be explained by less silane grafting due to the formation of siloxane oligomer attached to the first layer of reacted TESPT on particle surfaces which could further reduce the energy absorption capability of the MREs. Energy loss in the materials could also be attributed to interfacial friction of weakly or partially bonded iron sand particles and rubber with increasing frequency. It is also apparent that the G' for MREs with modified iron sand are higher compared to MREs with unmodified iron sand. Explanation for general increment of G' for MREs with modified iron sand could be related to efficient stress transfer between particles and matrix which can improve stiffness, strength and failure strain of the materials [46]. Furthermore, improved interfacial 
bonding and degree of iron sand particle dispersion in the matrix might increase the effective particle-matrix interfacial area such that increased constraint of polymer chains occurs during deformation and improved the ability of the material to store elastic energy associated with recoverable elastic deformation [47].

The variation of $\tan \delta$ with strain amplitude for MREs with different TESPT contents is shown in Figure 10a; G'and G” are also plotted in Figure 10 (b and c). As expected, MREs with modified iron sand treated with $6 \%$ TESPT had the highest $\tan \delta$ over the whole strain amplitude range explored with a $20 \%$ increase in $\tan \delta$ compared to MREs with unmodified iron sand. As can be observed in Figure 10 (a and b), the $\tan \delta$ and G' were amplitude dependent at low strain amplitudes before reaching a plateau, with the $\tan \delta$ for MREs with modified iron sand reaching a plateau at around $2.5 \%$ strain amplitude, whereas the $\tan \delta$ of the MREs with unmodified iron sand reached a plateau at $2 \%$ strain amplitude. It was evident that strong interfacial bonding between the iron sand and rubber as well as better dispersion increased the dependency of $\tan \delta$ on the amplitude of the applied strain and the change of $\tan \delta$ values over the strain amplitude range for all tested samples is mainly due to a decrease in G' as the strain amplitude increased. The decrease in G' as the strain amplitude increased for MREs with modified iron sand could be explained by the increase of particle detachment from the matrix with increasing strain amplitude. As can also be seen, G” for MREs with modified iron sand are higher compared to MREs with unmodified iron sand. The higher loss modulus could be attributed to the energy loss due to stress released after debonding and increase of energy absorbed during viscous flow which is more constrained due to formation of chemical linkages between iron sand and rubber. Once the strain amplitude is high enough, all the interactions are destroyed to such an extent it cannot be reconstructed and consequently, the energy loss is largely reliant on the viscous flow of the rubber matrix. 
Figure 11 presents the tan $\delta$ versus temperature curves for MREs with different TESPT contents. The $\tan \delta$ peak is associated with glass transition temperature (Tg) of the materials. In the glass transition zone, the energy dissipation is mainly from the segmental motion of macromolecular chain of rubber matrix in spite of breakdown of filler-filler or filler rubber interaction [48]. It can be seen that the presence of coupling agent does not strongly affect the peak height and width of the curves. This is in agreement with similar finding reported by other researchers $[23,49,50]$. However, an enlarged graph of the tan $\delta$ versus temperature around the peaks showed a slight decrease of the height of the $\tan \delta$ peak and the Tg values shifted to a slightly higher temperature for MREs with modified iron sand compared with MREs with unmodified iron sand. In addition, the decreased height of the tan $\delta$ peak was in an order similar to the silane grafting percentage as previously discussed. The decrease height of the damping peak and a shift of Tg to higher temperature could be attributed to strong filler rubber interaction which resulted in restriction in mobility and flexibility of rubber chains in the materials.

Figure 12 shows hysteresis loss for MREs with different TESPT contents. As can be seen, hysteresis loss increased with increasing TESPT content until it reached a maximum value at 6\% TESPT and thereafter decreased at higher TESPT content ( $8 \%$ and 10\%). The results are in agreement with the silane grafting percentage as previously discussed. The effect of coupling agent on the hysteresis loss of MREs could again be explained by the energy loss due to stress released after debonding and increase of energy absorbed during viscous flow which is more constrained due to formation of chemical linkages between iron sand and rubber. Some authors have considered constraint in liaise of a rubber shell mechanisms [13]. The molecular chain mobility would be reduced by the formation of silane linkages between iron sand and rubber, resulting in a rubber shell on the filler surface in which the polymer viscosity and Young modulus would be 
increased. The higher Young's modulus of rubber near the surface of iron sand in the rubber shell would gradually decrease with increased distance from the filler surface and finally reach the same level as that of the rubber matrix at a certain distance. When the MREs were subjected to dynamic strain, the rubber shell around the particles would begin to break down and increase the amount of energy loss. In addition, hysteresis loss could also be attributed to interfacial friction at the filler matrix interface and breakdown of filler aggregates. The decrease of hysteresis loss at higher TESPT content could again be explained by the lower silane grafting and formation of weak siloxane oligomer that may begin to break down at a relatively lower level of strain.

\section{CONCLUSION}

In this work, iron sand particles were modified at five different TESPT contents ( 2, 4, 6, 8 and 10 wt\%) relative to the iron sand content to assess the optimum amount of for use in MREs. TESPT contains ethoxy hydrolysable groups that enable bonding with iron sand particles and a tetrasulphane group capable of bonding with the rubber matrix. Raman spectroscopy showed evidence that siloxane linkages were formed between TESPT and iron sand. Weight loss measured using TGA supports that silane coupling agent is strongly bound to particle surfaces and the silane grafting percentage was found to be the highest at 6\% TESPT. Crosslink density measurement of MREs made using TESPT treated iron sand highlight that the tetrasulphane group of TESPT formed crosslinks with the rubber molecular chains. Treated iron sand was found to be more evenly dispersed in the rubber with much less particle pullout on fracture surface supporting improved interfacial adhesion with natural rubber. Tan $\delta$ was found to be highest for the MREs with modified iron sand treated with 6\% TESPT and 40\% larger than that unmodified iron sand over the whole frequency range explored and 20\% higher over the whole strain amplitude explored. However, the presence of coupling agent did not strongly affect the peak temperature of $\tan \delta$ versus temperature 
curves. An increase in hysteresis loss was also obtained for MREs with modified iron sand treated with 6\% TESPT content compared with MREs with unmodified iron sand.

\section{ACKNOWLEDGEMENTS}

The authors would like to thank for the support from the Polymer and Composite Research Group of the University of Waikato.

\section{REFERENCES}

[1] Chen L, Gong XL, Li WH. Effect of carbon black on the mechanical performances of magnetorheological elastomers. Polymer Testing. 2008;27(3):340-5.

[2] Chokkalingam R, Rajasabai Senthur P, Mahendran M. Magnetomechanical behavior of Fe/PU magnetorheological elastomers. Journal of Composite Materials. 2010;45(15):1545-52.

[3] Fuchs A, Zhang Q, Elkins J, Gordaninejad F, Evrensel C. Development and characterization of magnetorheological elastomers. Journal of Applied Polymer Science. 2007;105(5):2497-508.

[4] Ginder J. Magnetorheological elastomers: properties and applications. Proc SPIE. 1999;3675(1):131.

[5] Lerner AA, Cunefare KA. Performance of MRE-based Vibration Absorbers. Journal of Intelligent Material Systems and Structures. 2008;19(5):551-63.

[6] Sun TL, Gong XL, Jiang WQ, Li JF, Xu ZB, Li WH. Study on the damping properties of magnetorheological elastomers based on cis-polybutadiene rubber. Polymer Testing. 2008;27(4):520-6. [7] Wang Y, Hu Y, Deng H, Gong X, Zhang P, Jiang W, et al. Magnetorheological elastomers based on isobutylene-isoprene rubber. Polymer Engineering \& Science. 2006;46(3):264-8.

[8] Deng HX, Gong XL. Application of magnetorheological elastomer to vibration absorber. Communications in Nonlinear Science and Numerical Simulation. 2008;13(9):1938-47.

[9] Dyke SJ, Spencer JR, Sain MK, Carlson JD. Modeling and control of magnetorheological dampers for seismic response reduction. Smart Materials and Structures. 1996;5(5):565-75.

[10] Park JO, Rhee KY, Park SJ. Silane treatment of Fe3O4 and its effect on the magnetic and wear properties of Fe3O4/epoxy nanocomposites. Applied Surface Science.256(23):6945-50.

[11] Taghvaei AH, Shokrollahi H, Ebrahimi A, Janghorban K. Soft magnetic composites of iron-phenolic and the influence of silane coupling agent on the magnetic properties. Materials Chemistry and Physics. 2009;116(1):247-53.

[12] Tian Y, Liu Y, He M, Zhao G, Sun Y. High damping properties of magnetic particles doped rubber composites at wide frequency. Materials Research Bulletin.48(5):2002-5.

[13] Wang MJ. Effect of Polymer-Filler and Filler-Filler Interactions on Dynamic Properties of Filled Vulcanizates. Rubber Chemistry and Technology. 1998;71(3):520-89.

[14] Sun Y, Zhou X, Liu Y, Zhao G, Jiang Y. Effect of magnetic nanoparticles on the properties of magnetic rubber. Materials Research Bulletin. 2009;45(7):878-81.

[15] Jiang WQ, Yao JJ, Gong XL, Chen L. Enhancement in Magnetorheological Effect of Magnetorheological Elastomers by Surface Modification of Iron Particles. Chinese Journal of Chemical Physics. 2008;21(1):87-92. 
[16] Wu J, Gong X, Chen L, Xia H, Hu Z. Preparation and characterization of isotropic polyurethane magnetorheological elastomer through in situ polymerization. Journal of Applied Polymer Science. 2009;114(2):901-10.

[17] Xiuying Q, Xiushou L, Weihua L, Jun C, Xinglong G, Tao Y, et al. Microstructure and magnetorheological properties of the thermoplastic magnetorheological elastomer composites containing modified carbonyl iron particles and poly(styrene- $b$-ethylene-ethylenepropylene- $b$ styrene) matrix. Smart Materials and Structures.21(11):115028.

[18] Ansarifar A, Azhar A, Ibrahim N, Shiah SF, Lawton JMD. The use of a silanised silica filler to reinforce and crosslink natural rubber. International Journal of Adhesion and Adhesives. 2005;25(1):77-86.

[19] Choi SS, Kim IS, Woo CS. Influence of TESPT content on crosslink types and rheological behaviors of natural rubber compounds reinforced with silica. Journal of Applied Polymer Science. 2007;106(4):27538.

[20] Vinod VS, Varghese S, Kuriakose B. Degradation behaviour of natural rubber-aluminium powder composites: effect of heat, ozone and high energy radiation. Polymer Degradation and Stability. 2002;75(3):405-12.

[21] Rooj S, Das A, Thakur V, Mahaling RN, Bhowmick AK, Heinrich G. Preparation and properties of natural nanocomposites based on natural rubber and naturally occurring halloysite nanotubes.

Materials \& Design.31(4):2151-6.

[22] Ismail H, Abdul Khalil HPS. The effects of partial replacement of oil palm wood flour by silica and silane coupling agent on properties of natural rubber compounds. Polymer Testing. 2000;20(1):33-41.

[23] Zeng Z, Ren W, Xu C, Lu W, Zhang Y, Zhang Y. Effect of bis(3-triethoxysilylpropyl) tetrasulfide on the crosslink structure, interfacial adhesion, and mechanical properties of natural rubber/cotton fiber composites. Journal of Applied Polymer Science. 2009;111(1):437-43.

[24] Pickering KL, Abdalla A, Ji C, McDonald AG, Franich RA. The effect of silane coupling agents on radiata pine fibre for use in thermoplastic matrix composites. Composites Part A: Applied Science and Manufacturing. 2003;34(10):915-26.

[25] Wang YL, Hu YA, Chen L, Gong XL, Jiang WQ, Zhang PQ, et al. Effects of rubber/magnetic particle interactions on the performance of magnetorheological elastomers. Polymer Testing. 2006;25(2):262-7. [26] Possinger T, Bolzmacher C, Bodelot L, Triantafyllidis N. Interfacial adhesion between the iron fillers and the silicone matrix in magneto-rheological elastomers at high deformations. p. 87631Y-Y-11.

[27] Monticelli F, Toledano M, Osorio R, Ferrari M. Effect of temperature on the silane coupling agents when bonding core resin to quartz fiber posts. Dental Materials. 2006;22(11):1024-8.

[28] Yakobi HJD, Ladino LA, Abbatt JPD. Feldspar minerals as efficient deposition ice nuclei. Atmos Chem Phys Discuss.13(6):17299-326.

[29] Puvanakrishnan R, Bose SM, Reddi BR. Immobilization of trypsin on sand: Mode of binding. Journal of Biosciences. 1982;4(1):51-9.

[30] Lakes RS. High Damping Composite Materials: Effect of Structural Hierarchy. Journal of Composite Materials. 2001;36(3):287-97.

[31] Khimi SR, Pickering KL. A new method to predict optimum cure time of rubber compound using dynamic mechanical analysis. Journal of Applied Polymer Science. 2013;131(6):40008(1-6).

[32] Guo ZX, Yu J. Grafting of dendritic polyethers onto nanometre silica surface. Journal of Materials Chemistry. 2002;12(3):468-72.

[33] Zhao J, Milanova M, Warmoeskerken MMCG, Dutschk V. Surface modification of TiO2 nanoparticles with silane coupling agents. Colloids and Surfaces A: Physicochemical and Engineering

Aspects.413(0):273-9.

[34] Flory PJ, Rehner J. Statistical Mechanics of Cross-Linked Polymer Networks II. Swelling. The Journal of Chemical Physics. 1943;11(11):521-6. 
[35] Hunsche A, Gorl U, Muller A, Knaack M, Gobel T. Investigations concerning the reaction silica/organosilane and organosilane/polymer. Part 1: Reaction mechanism and reaction model for silica/organosilane. Kautschuk und Gummi, Kunststoffe. 1997;50(12):881-9.

[36] Hunsche A, Gorl U, Koban HG, Lehmann T. Investigations on the reaction silica/organosilane and organosilane/polymer. Part 2: Kinetic aspects of the silica-organosilane reaction. Kautschuk und Gummi, Kunststoffe. 1998;51(7-8):525-33.

[37] Shebanova ON, Lazor P. Raman study of magnetite (Fe3O4): laser-induced thermal effects and oxidation. Journal of Raman Spectroscopy. 2003;34(11):845-52.

[38] Shih PTK, Koenig JL. Raman studies of the hydrolysis of silane coupling agents. Materials Science and Engineering. 1975;20(0):137-43.

[39] Amanda A, Julio BA, Gemma LD, Yurii KG, Nuria V, Xavier MB, et al. Ecologically Friendly PolymerMetal and Polymer-Metal Oxide Nanocomposites for Complex Water Treatment.

[40] Hou Y, Yu J, Gao S. Solvothermal reduction synthesis and characterization of superparamagnetic magnetite nanoparticles. Journal of Materials Chemistry. 2003;13(8):1983-7.

[41] Zhang H, Li C, Guo J, Zang L, Luo J. In Situ Synthesis of Poly(methyl methacrylate)/SiO2 Hybrid Nanocomposites via "Grafting Onto" Strategy Based on UV Irradiation in the Presence of Iron Aqueous Solution. Journal of Nanomaterials. 2011;2012:1-9.

[42] Sideridou ID, Karabela MM. Effect of the amount of 3-methacyloxypropyltrimethoxysilane coupling agent on physical properties of dental resin nanocomposites. Dental Materials. 2009;25(11):1315-24.

[43] Choi SS. Influence of storage time and temperature and silane coupling agent on bound rubber formation in filled styrene butadiene rubber compounds. Polymer Testing. 2002;21(2):201-8.

[44] Gorl U, Munzenberg J, Luginsland D, Muller A. Investigations on the reaction silica/organosilane and organosilane/polymer-Part 4: Studies on the chemistry of the silane sulfur chain. Kautsch Gummi Kunstst. 1999;52(9):588-97.

[45] Luginsland HD. Reactivity of the sulfur chains of the tetrasulfane silane Si 69 and the disulfane silane TESPD. Kautsch Gummi Kunstst. 2000;53(1):10-9.

[46] Sun L, Gibson RF, Gordaninejad F, Suhr J. Energy absorption capability of nanocomposites: A review. Composites Science and Technology. 2009;69(14):2392-409.

[47] Gu H, Guo Y, Wong SY, He C, Li X, Shim VPW. Effect of interphase and strain-rate on the tensile properties of polyamide 6 reinforced with functionalized silica nanoparticles. Composites Science and Technology.75(0):62-9.

[48] Li Y, Han B, Liu L, Zhang F, Zhang L, Wen S, et al. Surface modification of silica by two-step method and properties of solution styrene butadiene rubber (SSBR) nanocomposites filled with modified silica. Composites Science and Technology. 2013;88(1):69-75.

[49] Mele P, Marceau S, Brown D, Puydt DY, Alberola ND. Reinforcement effects in fractal-structurefilled rubber. Polymer. 2002;43(20):5577-86.

[50] Li Y, Han B, Liu L, Zhang F, Zhang L, Wen S, et al. Surface modification of silica by two-step method and properties of solution styrene butadiene rubber (SSBR) nanocomposites filled with modified silica. Composites Science and Technology.88(0):69-75. 


\section{FIGURE CAPTIONS}

Figure 1 Molecular structure of TESPT

Figure 2 Illustration of the reactions of TESPT with iron sand particle surface.

Figure 3 Raman spectra of iron sand particles at different TESPT contents

Figure 4 TGA curves for iron sand particles at different TESPT contents

Figure 5 Silane grafting percentage for iron sand particles at different TESPT contents 
Figure 6 Schematic illustration of the reaction mechanisms of tetrasulphane group of TESPT with the natural rubber $\left(\mathrm{S}_{2} \bullet\right.$ represents sulfidic radicals of tetrasulphane group of TESPT) Figure 7 Crosslink density of MREs with different TESPT contents.

Figure 8 SEM images of fracture surface of isotropic MREs with; (a) unmodified and (b) modified iron sand particles (treated with 6\% TESPT)

Figure 9 (a) Tan $\delta$, (b) storage modulus (G') and (c) loss modulus (G”) vs. frequency for MREs with different TESPT contents.

Figure 10 (a) Tan $\delta$, (b) storage modulus (G') and (c) loss modulus (G”) vs. strain amplitude for MREs with different TESPT contents.

Figure 11 Tan $\delta$ versus temperature curves for MREs with different TESPT contents.

Figure 12 Hysteresis loss for MREs with different TESPT contents.

\section{TABLE CAPTION}

Table 1 Formulation of rubber compound

Table 1

\begin{tabular}{llcccccc}
\hline Materials & Function & \multicolumn{7}{c}{ loading (phr) } \\
\hline natural rubber & raw material/matrix & 100 & 100 & 100 & 100 & 100 & 100 \\
ZnO & activator/peptiser & 5 & 5 & 5 & 5 & 5 & 5 \\
stearic acid & activator/peptiser & 1 & 1 & 1 & 1 & 1 & 1 \\
paraffin oil & plasticiser & 2 & 2 & 2 & 2 & 2 & 2 \\
naphthenic oil & plasticiser & 3 & 3 & 3 & 3 & 3 & 3 \\
iron sand & filler & 70 & 70 & 70 & 70 & 70 & 70 \\
CBS & accelerator & 2 & 2 & 2 & 2 & 2 & 2 \\
TMTD & accelerator & 1 & 1 & 1 & 1 & 1 & 1
\end{tabular}




\begin{tabular}{lccccccc} 
sulphur & crosslinking agent & 1.5 & 1.5 & 1.5 & 1.5 & 1.5 & 1.5 \\
\hline $\begin{array}{l}\text { Silane coupling agent level (wt \%) } \\
\text { TESPT }\end{array} \quad$ coupling agent & 0 & 2 & 4 & 6 & 8 & 10 \\
\hline $\begin{array}{l}\text { Curing characteristics (minutes) } \\
\text { Cure time } \quad\left(\mathrm{t}_{90}\right)\end{array}$ & 4.57 & 4.53 & 4.33 & 4.23 & 4.40 & 4.46 \\
\hline
\end{tabular}

$*$ phr $=$ per hundred rubber

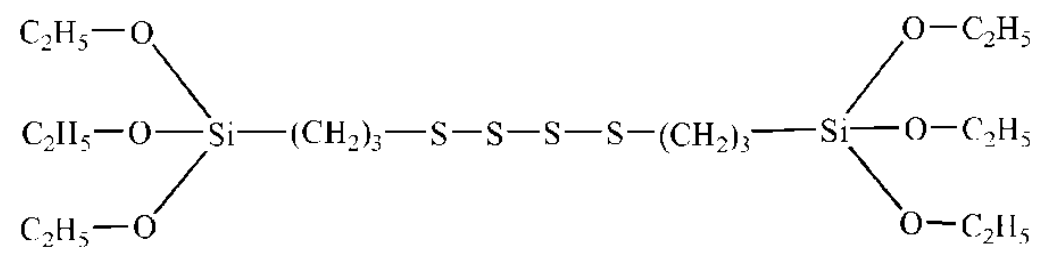

Figure 1 


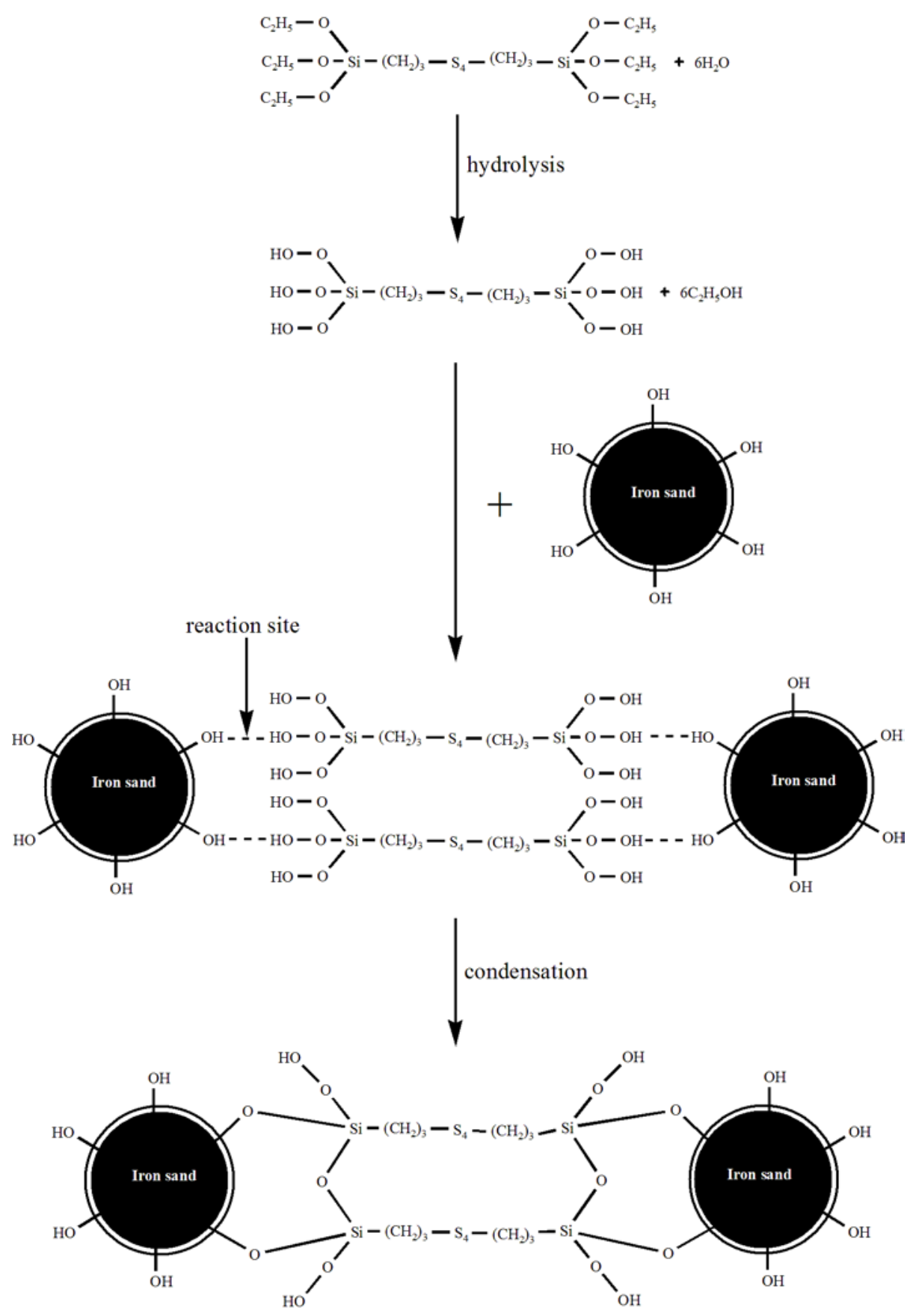

Figure 2 


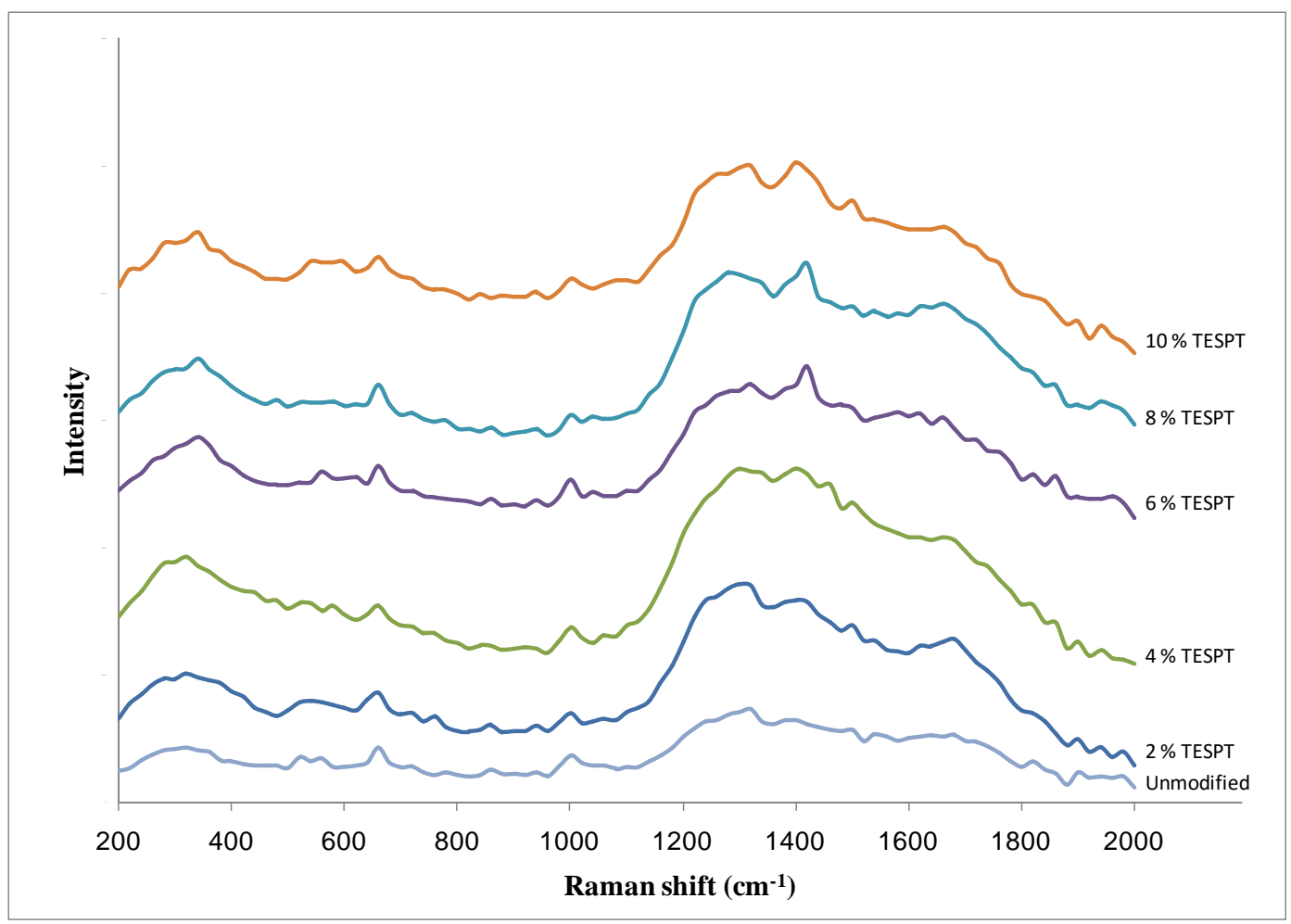

Figure 3

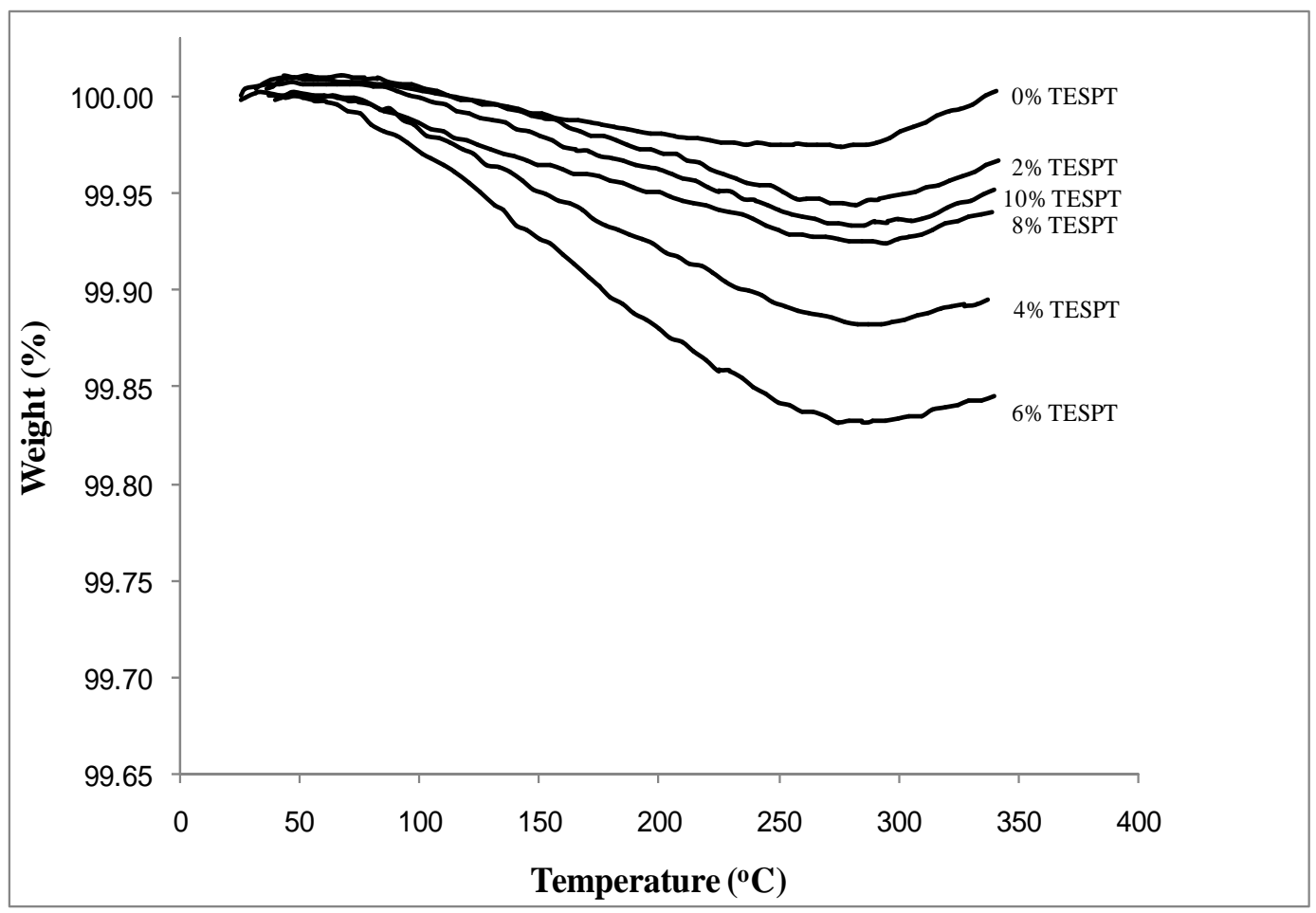

Figure 4 


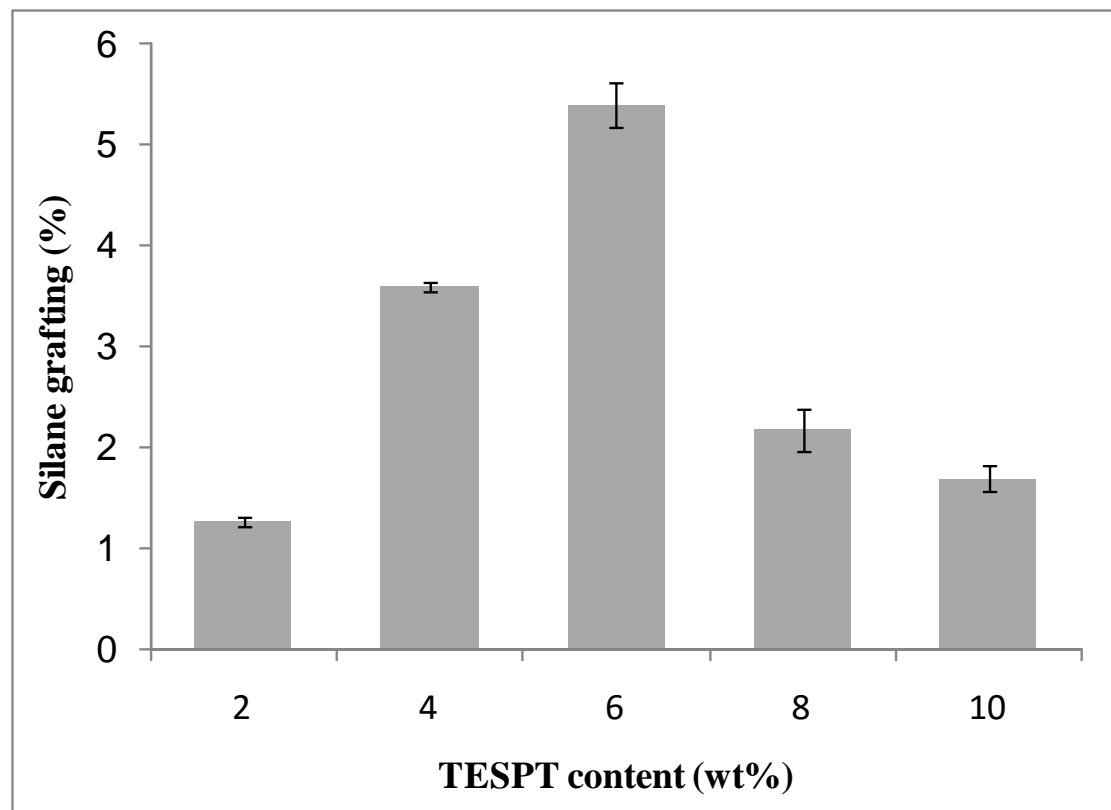

Figure 5 


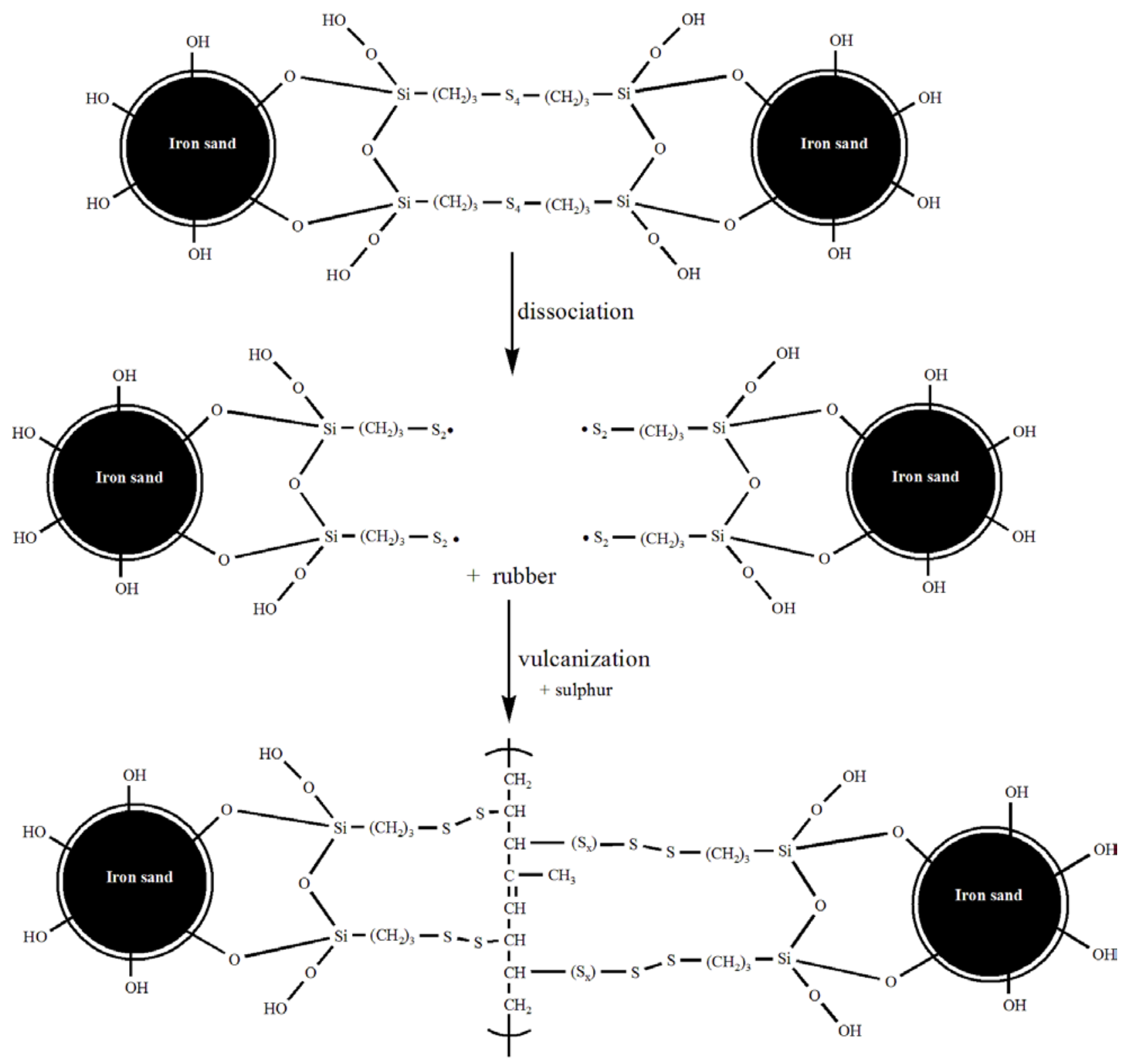

Figure 6 


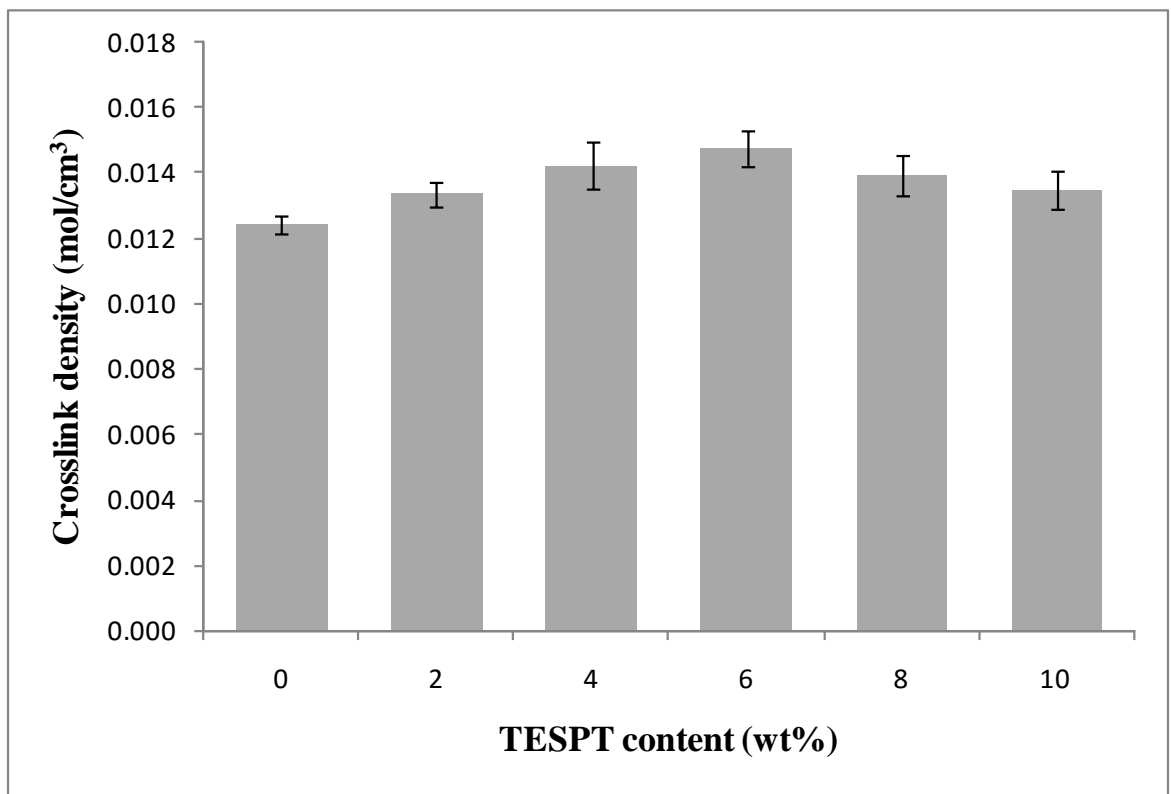

Figure 7 

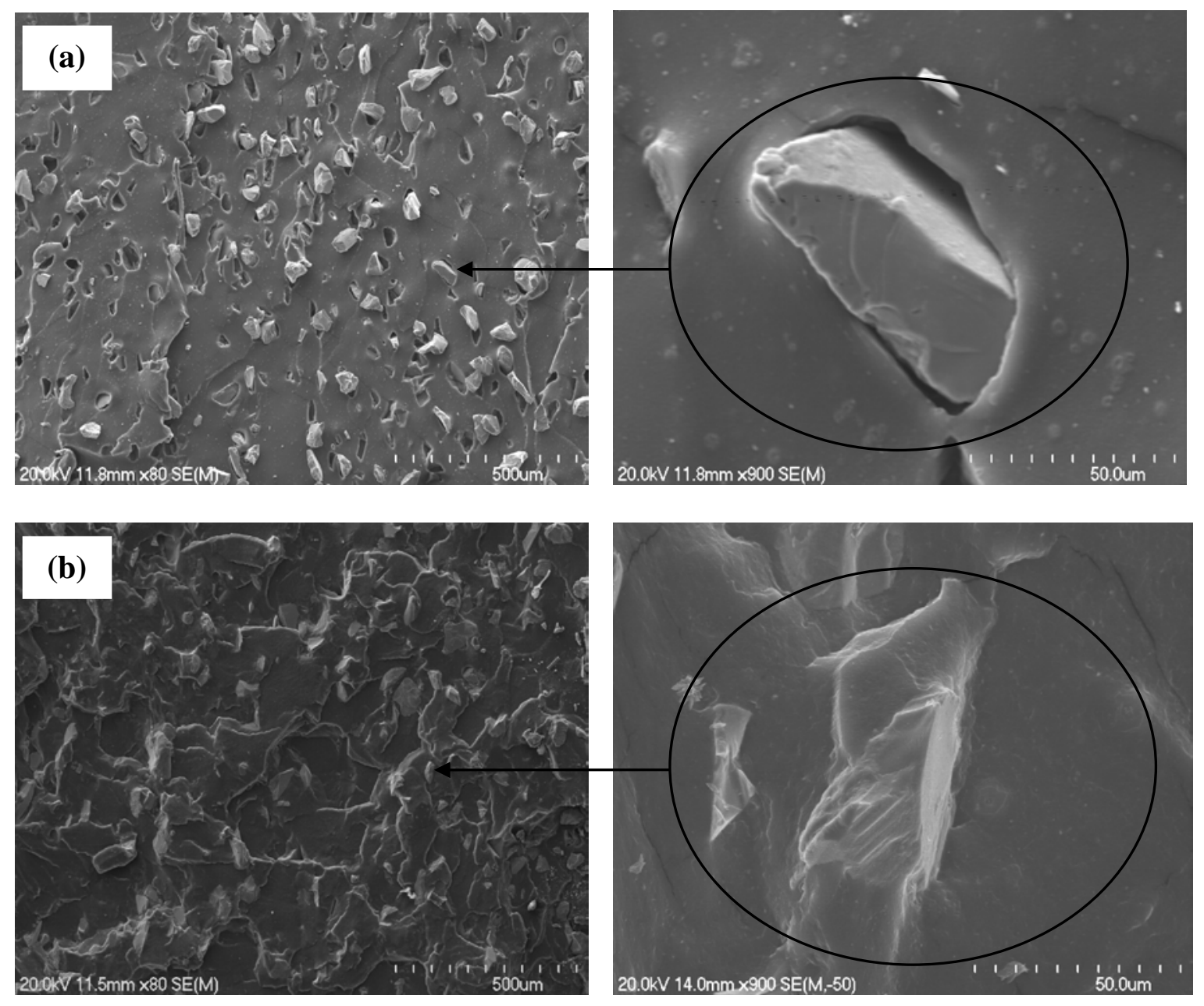

Figure 8 


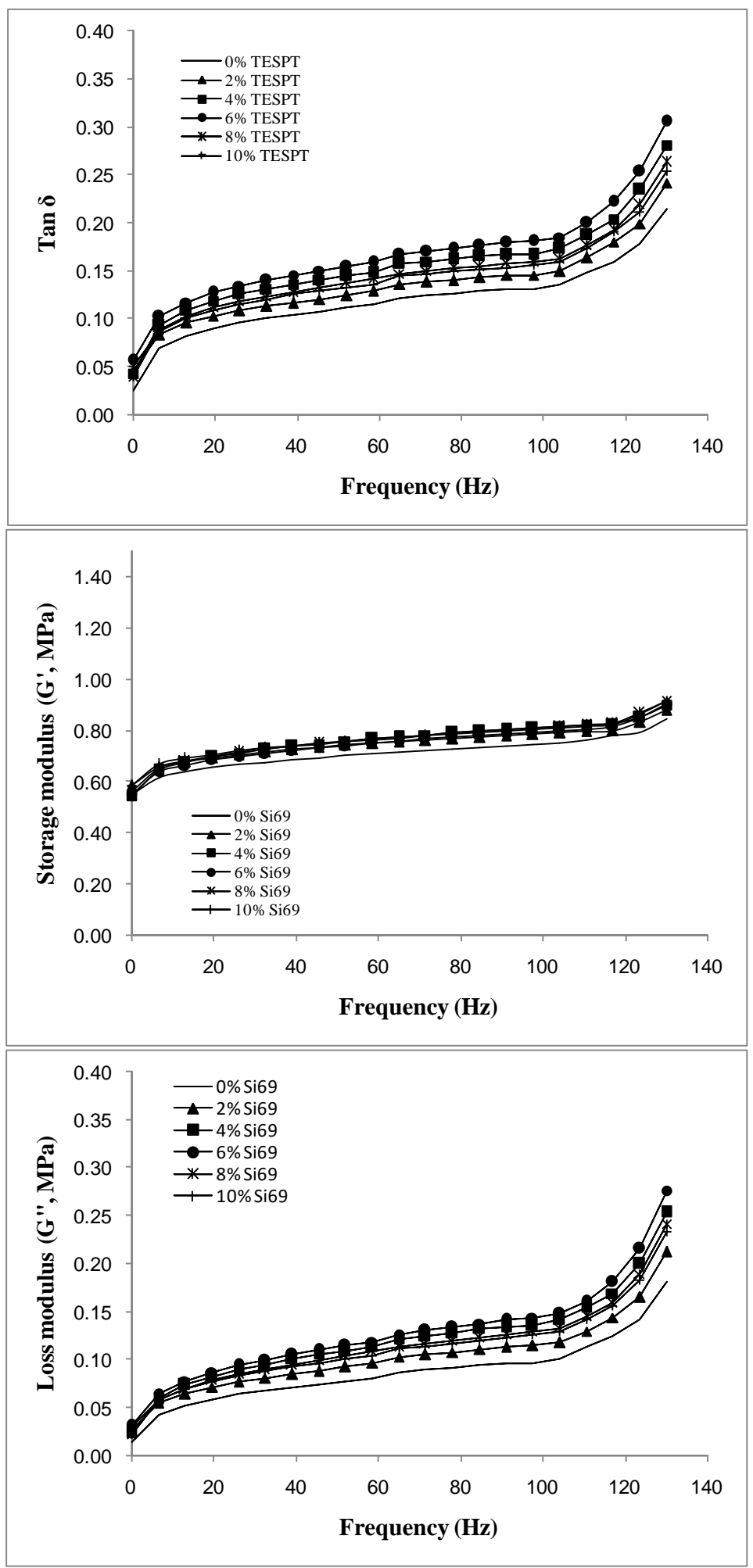

Figure 9 

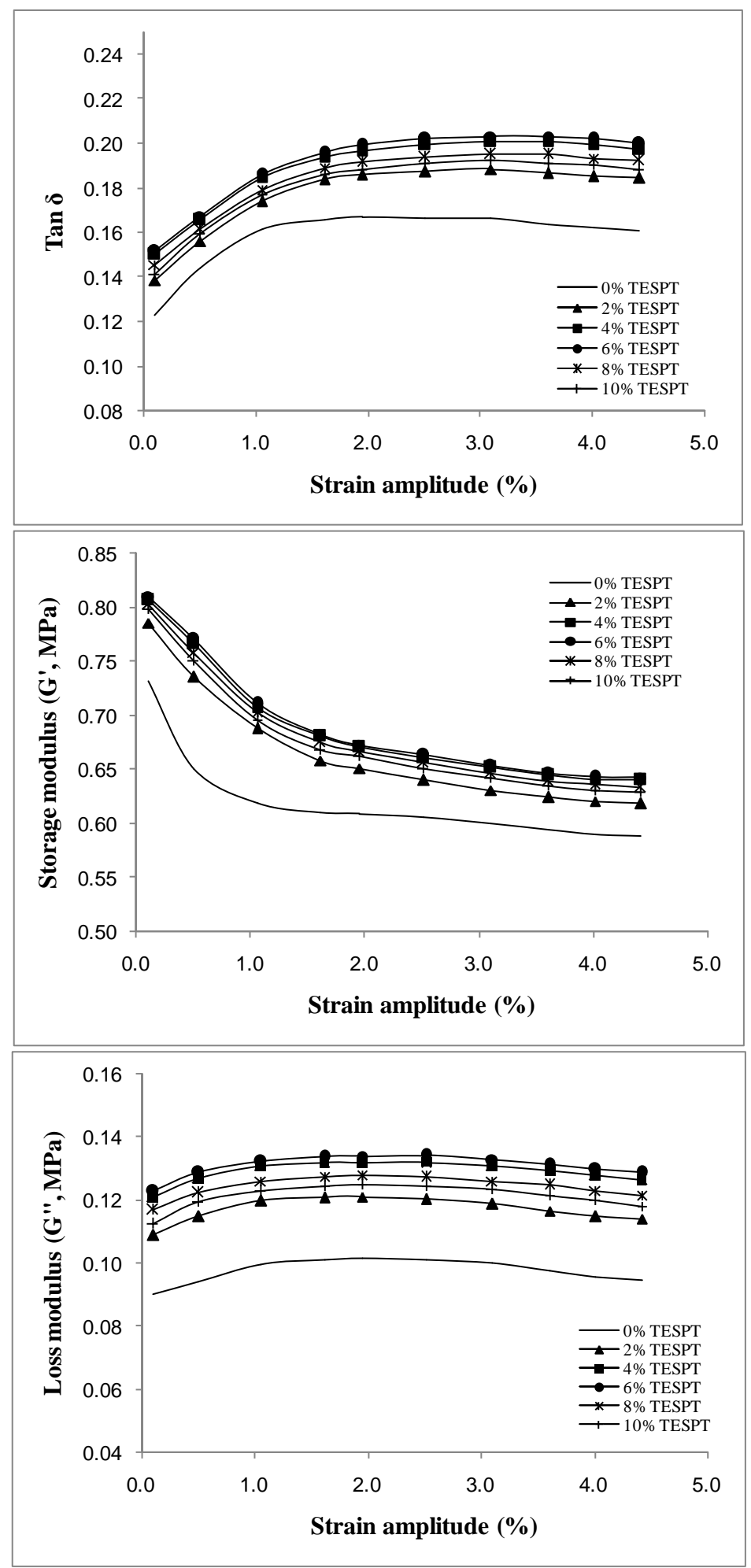

Figure 10 


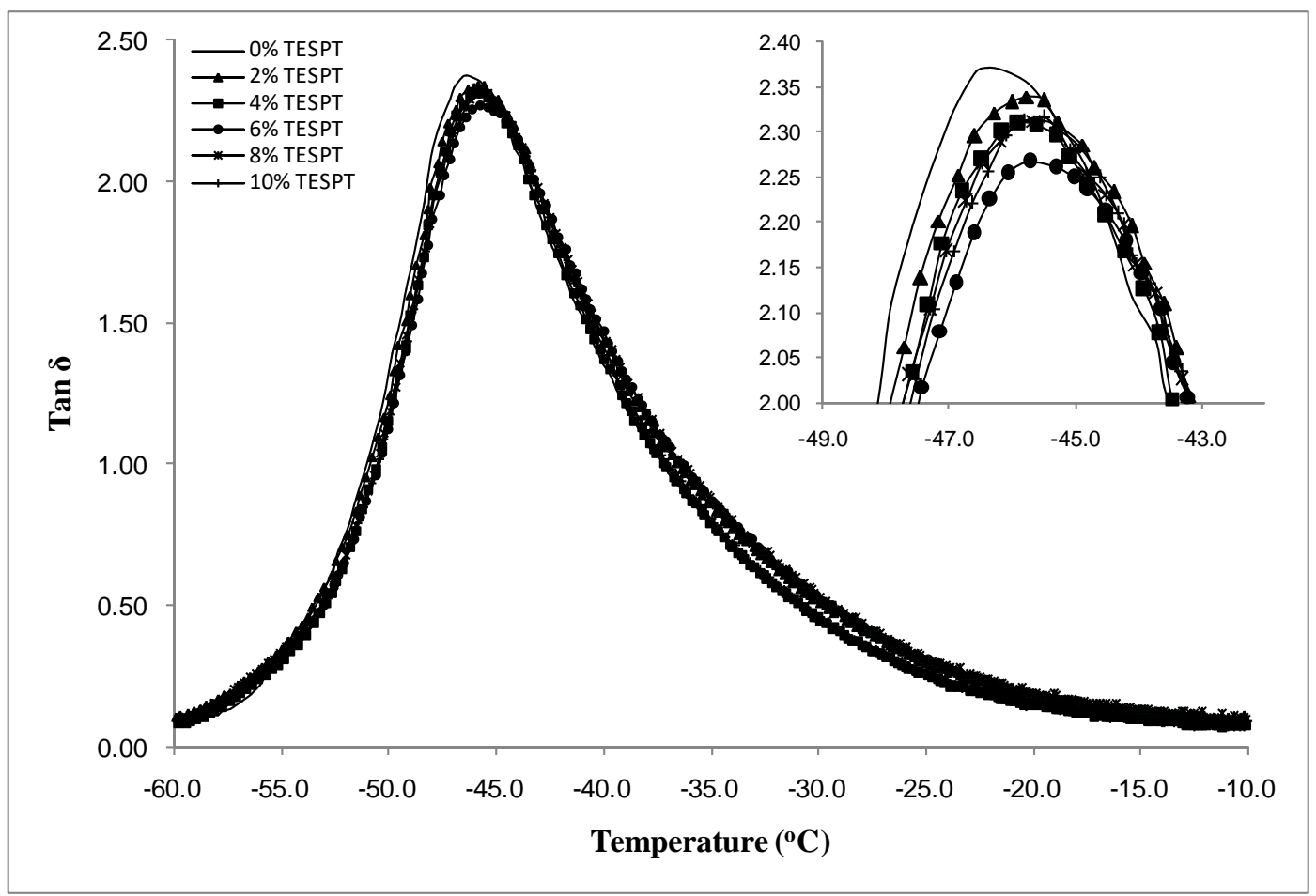

Figure 11

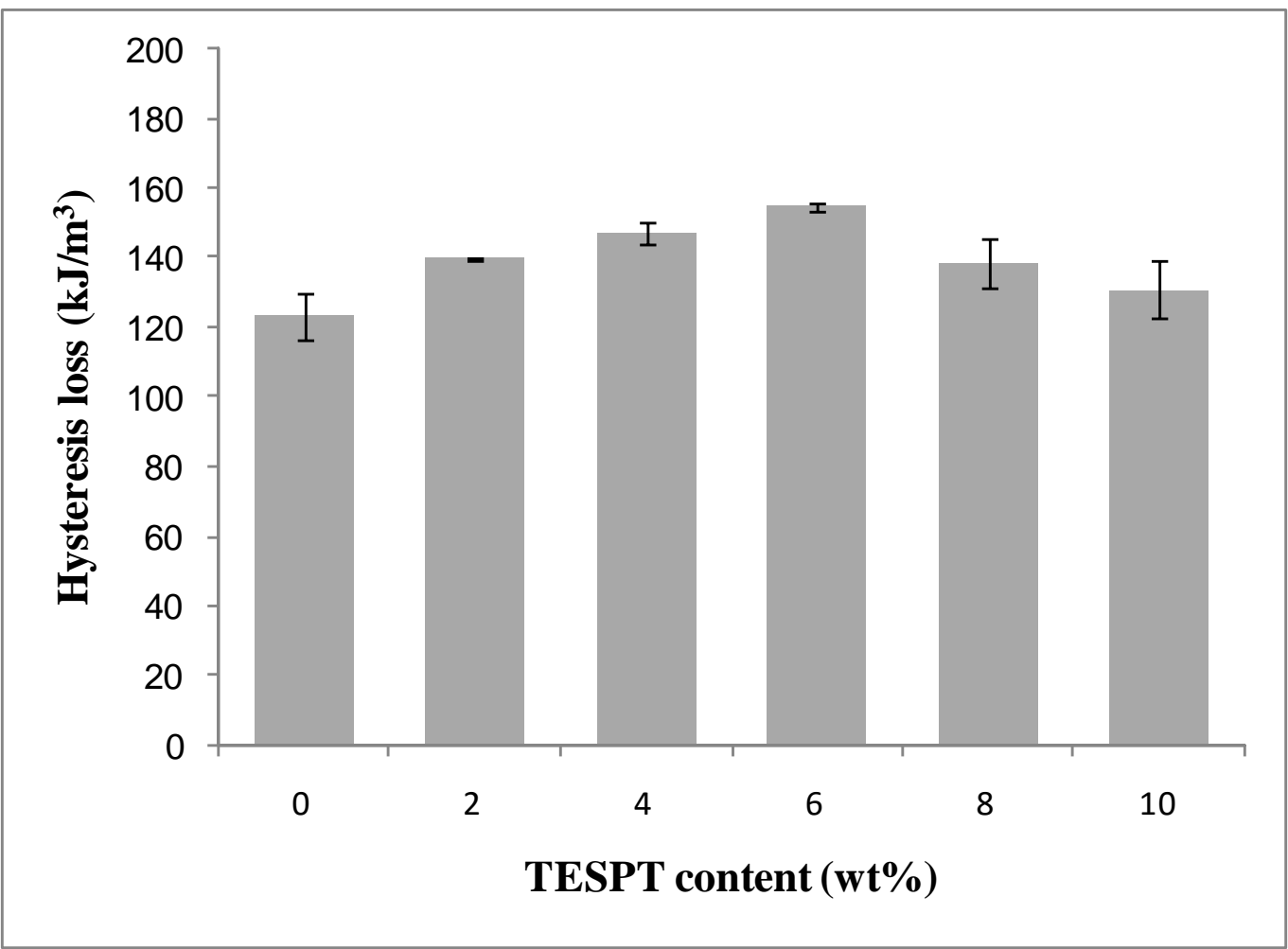

Figure 12 